\section{Suicide in psychiatric hospital in-patients}

\author{
Risk factors and their predictive power \\ JOHN POWELL, JOHN GEDDES, JONATHAN DEEKS, MICHAEL GOLDACRE \\ and KEITH HAWTON
}

\begin{abstract}
Background Psychiatrichospital inpatients are known to be at high risk of suicide, yet there is little reliable knowledge of risk factors or their predictive power.
\end{abstract}

\begin{abstract}
Aims To identify risk factors for suicide in psychiatric hospital in-patients and to evaluate their predictive power in detecting people at risk of suicide.
\end{abstract}

Method Using a case-control design, II2 people who committed suicide while in-patients in psychiatric hospitals were compared with $1 / 2$ randomly selected controls. Univariate analysis and multivariate analyses were used to estimate odds ratios and adjusted likelihood ratios.

Results The rate of suicide in psychiatric in-patients was 13.7 (95\% CI II.7-16.I) per 10000 admissions. There were five predictive factors with likelihood ratios $>2$, following adjustment: planned suicide attempt, 4.I ; actual suicide attempt, 4.9; recent bereavement, 4.0; presence of delusions, 2.3; chronic mental illness, 2.2; and family history of suicide, 4.6. On this basis, only two of the patients who committed suicide had a predicted risk of suicide above $5 \%$.

\section{Conclusions Although several factors} were identified that were strongly associated with suicide, their clinical utility is limited by low sensitivity and specificity, combined with the rarity of suicide, even in this high-risk group.

Declaration of interest No conflict of interest. Financial support detailed in Acknowledgements.
Psychiatric hospital in-patients are known to be at high risk of suicide (Appleby, 1992). The National Confidential Inquiry into Suicide and Homicide by People with Mental Illness has identified in-patients as a priority group for whom service recommendations are most required, and has recommended that the risk assessment skills of clinical staff should be strengthened (Appleby et al, 1999a). There is a need to identify more clearly the factors that are associated with suicide among in-patients. However, suicidal behaviour is difficult to predict (Hawton, 1987; Geddes, 1999), and the risk factors in in-patients are not necessarily the same as the risk factors for suicide in other population groups. Uncontrolled studies of in-patient suicides cannot quantify such risk factors and there have been few case-control studies (Modestin et al, 1992; Read et al, 1993; Roy \& Draper, 1995; Sharma et al, 1998). We report a study designed to identify potential risk factors and to assess their clinical utility in the prediction of suicide.

\section{METHOD}

\section{Identification of subjects and controls}

Using the Oxford Record Linkage Study (ORLS) (Goldacre et al, 1988) we identified all the people who died while patients in psychiatric hospitals in the counties of Oxfordshire, Berkshire, Buckinghamshire and Northamptonshire between 1963 and 1992. We did this by linking death certificates to abstracts of records of psychiatric in-patient care. This enabled us to identify not only the deaths that occurred in psychiatric hospitals, but also those that occurred off the hospital site, of people who were in-patients at the time of their death. The records from two hospitals were excluded (one hospital had not recorded any cases of deaths of in-patients on the ORLS and the other had destroyed all medical records of patients who died before 1988). Any deaths occurring more than a year after admission were excluded, as this group was not considered to be representative of acute psychiatric admissions. The death certificates and coroners' records were examined to determine the cases of suicide. We included as suicides, cases where the coroner's verdict was suicide, or undetermined cause (open verdict), in line with conventional practice (Blain \& Donaldson, 1995). The causes of death were checked from examination of clinical records.

Using the ORLS, control subjects were randomly selected by computer from psychiatric hospital in-patients admitted to the same hospitals in the same period who had not committed suicide. As there are no reliably known risk factors for suicide in in-patients in psychiatric hospitals, controls were unmatched other than for the year of admission. Patients with dementia admitted for respite care were excluded from the control group as they were not considered to be representative of acute psychiatric admissions.

\section{Data collection}

Permission to examine clinical records was given by the responsible consultant psychiatrists and clinical directors. Case notes were obtained from medical records departments. Clinical and social data were recorded from the ORLS database and from examination of case notes by one researcher (J.P.), using a 74-item questionnaire which incorporated characteristics previously shown or postulated to be factors associated with subsequent suicide (Appleby, 1992). These factors were operationally defined for the purposes of the study. To measure the degree of suicidal ideation, we developed a four-point scale on which patients were rated (on the evidence of their case notes) as having: no suicidal ideation; some suicidal ideas but no plan; a plan, but which was not acted upon; an act of self-harm either leading to, or during, admission.

The questionnaire was developed in a pilot study. The OPCRIT computerised diagnostic classification questionnaire (McGuffin et al, 1991) was completed for all subjects, in addition to the clinical diagnosis recorded from the case notes. Data were recorded anonymously and transferred to a spreadsheet for analysis. It was not feasible for the rater to be blind to whether a subject was a case or a control, because this would have meant excluding important 
case-note material from the study. Ethical approval for the study was obtained from the local ethics committee.

\section{Statistical analysis}

Risk factor analysis

Descriptive analyses were carried out using SPSS (SPSS, 1997) and EPI-INFO (Dean et al, 1995). Univariate and multivariate analyses were carried out using logistic regression with EGRET and STATA computer software (StataCorp, 1999; Statistics and Epidemiology Research Corporation, 1991). Factors that were statistically significantly associated with suicide in the univariate analysis were adjusted for the presence of suicidal ideation, which was strongly associated with suicide. Results are reported as univariate and multivariate odds ratios with $95 \%$ confidence intervals (CIs).

\section{Likelihood ratio analysis}

To estimate the clinical usefulness of the risk factors that were identified, we calculated likelihood ratios (LRs) for the variables that were associated with suicide following adjustment for suicidal ideation. LRs express the predictive value of each risk factor by comparing the probability that an individual who committed suicide would have that feature, compared with a control. LRs $>1$ indicate increased risk of suicide, LRs $<1$ indicate evidence against suicide; and more extreme values indicate stronger evidence.

Bayes' theorem states that the post-test odds of a condition, given the presence of a risk factor, can be found by multiplication of pre-test odds by the appropriate LR for that risk factor. Direct application of the LRs from more than one risk factor could be achieved by using extensions of Bayes' theorem such as:

$$
\begin{aligned}
& \text { post-test odds }=\mathrm{LR}_{1} \times \mathrm{LR}_{2} \times \ldots \times \mathrm{LR}_{\mathrm{n}} \\
& \quad \times \text { pretest odds }
\end{aligned}
$$

However, such an approach has been termed 'naïve' or 'idiot's Bayes' (Feinstein, 1977), as it does not account for the double counting of evidence from related risk factors. In practice, it typically overcounts diagnostic or predictive evidence and produces over-predictive models. A multivariate method to adjust for such confounding while preserving expression of the results in terms of LRs has been developed (Spiegelhalter \& Knill-Jones,
1984). Noting that the 'naïve Bayes' model can be written in terms of a sum of log likelihood ratios $\left(\mathrm{LLR}_{\mathrm{i}}\right)$ :

$$
\begin{aligned}
& \text { post-test log odds }=\mathrm{LLR}_{1}+\mathrm{LLR}_{2}+\ldots+ \\
& \mathrm{LLR}_{\mathrm{n}}+\text { pretest log odds }
\end{aligned}
$$

the confounding can be adjusted for by 'shrinking' each of the $\operatorname{LLR}_{\mathrm{i}} \mathrm{s}$ by factors $\mathrm{S}_{\mathrm{i}}$ :

$$
\begin{aligned}
& \text { post-test log odds }=\left(S_{1} \times L_{L R}\right)+ \\
& \left(S_{2} \times L_{L} R_{2}\right)+\ldots+\left(S_{n} \times L_{L R}\right)+ \\
& \text { pretest log odds }
\end{aligned}
$$

Estimates of $S_{i}$ are obtained by logistic regression, and the adjusted LRs can be obtained by back-transformation. Such a model does not account for any interaction of diagnostic elements, solely confounding. A reduced multivariate model was produced by retaining only risk factors with adjusted LRs of 2 or more from the odds ratios logistic regression. Using these with the baseline suicide rate for in-patients allowed us to estimate the post-test probabilities of the predictor variables.

\section{RESULTS}

In the study period there were 117 deaths of psychiatric hospital in-patients in which a suicide or open verdict was given by the coroner. The estimated suicide rate was 13.7/10 000 admissions (95\% CI 11.716.1). When the medical case notes were examined, it was found that in two cases an open verdict had been recorded in circumstances other than suicide, and that in three further cases the act of suicide had taken place immediately prior to admission to hospital (two concealed overdoses) or immediately following discharge, leaving 112 identified cases of in-patient suicide. Case notes were found for $97 \mathrm{pa}$ tients $(87 \%)$. The characteristics of the in-patient suicides are summarised in Table 1. Case notes were found for 90 of 112 controls $(80 \%)$.

\section{Characteristics of the suicides}

As shown in Table 1, more suicides occurred at the weekend. However, this excess was reduced from $61 \%$ to $15 \%$ when patients officially on weekend leave were excluded. Seventy-two per cent $(n=70)$ of suicides of in-patients took place outside the hospital site; $63 \%$ of these patients were absent without leave. The most common method of suicide was drowning, with 28 drownings in rivers or lakes and three in baths on the ward. More men than women used violent methods, such as being hit by a train, or cutting or burning themselves; men were also more likely to use carbon monoxide or suffocation. The number of suicides by overdose was small $(11 \%, n=11)$. Twenty-six per cent $(n=25)$ of the in-patients not on leave were on formal nursing observations at the time of suicide, and two in-patients were under continuous observation. One of these two jumped through a window and deliberately cut his neck with the broken glass, the other ran to a railway line and was hit by a train.

\section{Comparison of cases and controls}

Univariate analyses comparing potential risk factors between cases and controls are shown in Table 2. The strongest risk factor for suicide was suicidal thoughts or acts prior to admission (as recorded in the case notes), and there was a 'dose-response' between the level of suicidal thoughts or acts and the degree of risk (likelihood ratio statistic for trend 53.71, 1 d.f., $P<0.001$ ). Patients who had harmed themselves either before or during admission were much more likely to commit suicide than control patients (OR 14.3; 95\% CI 6.4-31.8). Other factors that remained significantly associated with suicide, after adjustment for the degree of suicidal thoughts or acts, were: recent bereavement (death of significant person in previous 12 months); presence of delusions; hopelessness; previous self-harm (before the index episode); chronic mental illness of over five years' duration (excluding diagnosis of personality disorder); previous admission to psychiatric hospital; and history of suicide in a first-degree relative. Patients with current drug or alcohol abuse were less likely to kill themselves.

\section{Likelihood ratios}

The crude LRs (with 95\% CI) and LRs adjusted for the variables that were positively associated with suicide, and the post-test probabilities of each predictor using the observed pretest probability of 13.7 per $10000(0.137 \%)$ are presented in Table 3. The final model (including factors with adjusted LRs $>2$ ) included five predictors: recent bereavement, presence of delusions, suicidal ideation, chronic mental illness and a family history 
Table I Characteristics of people who committed suicide while in in-patient care

\begin{tabular}{|c|c|c|c|}
\hline & $\begin{array}{c}\text { Men } \\
n=47(\%)\end{array}$ & $\begin{array}{l}\text { Women } \\
n=50(\%)\end{array}$ & $\begin{array}{c}\text { All } \\
n=97(\%)\end{array}$ \\
\hline Mean age (years) (s.d.) & $43.3(14.6)$ & $46.8(15.1)$ & $45.1(14.9)$ \\
\hline \multicolumn{4}{|l|}{ Coroner's verdict } \\
\hline Suicide & $25(53)$ & $27(54)$ & $52(54)$ \\
\hline Open & $22(47)$ & $23(46)$ & $45(46)$ \\
\hline \multicolumn{4}{|l|}{ Day of week of suicide } \\
\hline Monday & $5(\mathrm{II})$ & $10(20)$ & $15(15)$ \\
\hline Tuesday & $9(19)$ & $4(8)$ & $13(13)$ \\
\hline Wednesday & $6(13)$ & $3(6)$ & $9(9)$ \\
\hline Thursday & $6(13)$ & $5(10)$ & II (II) \\
\hline Friday & $3(6)$ & $8(16)$ & II (II) \\
\hline Saturday & $8(17)$ & $9(18)$ & $17(18)$ \\
\hline Sunday & $10(2 I)$ & II (II) & $2 I(22)$ \\
\hline \multicolumn{4}{|l|}{ Time of day } \\
\hline $08.00-12.00$ & $10(2 I)$ & $17(34)$ & $27(28)$ \\
\hline $12.00-16.00$ & $10(2 I)$ & $10(20)$ & $20(2 I)$ \\
\hline $16.00-20.00$ & $3(6)$ & $5(10)$ & $8(8)$ \\
\hline $20.00-24.00$ & $4(9)$ & $6(12)$ & $10(10)$ \\
\hline $24.00-04.00$ & $4(9)$ & $6(12)$ & $10(10)$ \\
\hline $04.00-08.00$ & $3(6)$ & $3(6)$ & $6(6)$ \\
\hline Unknown & $9(19)$ & $5(12)$ & $14(14)$ \\
\hline \multicolumn{4}{|l|}{ Method of suicide } \\
\hline Drowning & $8(17)$ & $23(46)$ & $31(32)$ \\
\hline Hanging & $8(17)$ & $7(14)$ & $15(15)$ \\
\hline Hit by train & $9(19)$ & $4(8)$ & $13(13)$ \\
\hline Jumping from height & $3(6)$ & $7(14)$ & $10(10)$ \\
\hline Overdose & $4(9)$ & $7(14)$ & II (II) \\
\hline Carbon monoxide & $7(15)$ & 0 & $7(7)$ \\
\hline Other suffocation & $4(9)$ & 0 & $4(4)$ \\
\hline Cut throat & $2(4)$ & 0 & $2(2)$ \\
\hline Burning & I (2) & 0 & $I(I)$ \\
\hline Not recorded & $I(2)$ & $2(4)$ & $3(3)$ \\
\hline \multicolumn{4}{|l|}{ Location of suicide } \\
\hline Within hospital site & II (23) & $14(28)$ & $25(26)$ \\
\hline Outside hospital site & $36(77)$ & $36(72)$ & $72(74)$ \\
\hline On leave & $34(72)$ & $36(72)$ & $70(72)$ \\
\hline
\end{tabular}

of suicide. In principle, these LRs can be used sequentially. For example, a patient with all five predictors would have a posttest odds of committing suicide of $(0.137)$ $100-0.137) \times 4.9 \times 3.9 \times 2.2 \times 2.2 \times 4.6=0.60$, or a probability of suicide of $37 \%$. Only one patient in the data set had all five risk factors.

Assuming a notional level of 'high risk' as being greater than a $5 \%$ probability of suicide, the model predicted the cases as shown in Table 4. This table demonstrates that the model is of low sensitivity: only $297(2 \%)$ of patients who committed suicide would have been identified as

having a $>5 \%$ risk of suicide. Twentyseven per cent $(26 / 97)$ of the patients who committed suicide had predicted risks of suicide greater than $1 \%$, as did $1 \%(1 / 90)$ of the controls. The estimated median level of risk of suicide in the patients committing suicide was less than $0.5 \%$.

If a $5 \%$ risk of suicide is considered to be clinically important, then the present data set would suggest that a patient with any three (or delusions plus chronic mental illness plus two others) or more of the five predictors should be considered to be at reasonably high risk. Patients with two (or delusions plus chronic illness plus one other) or more factors have risks of suicide greater than $1 \%$.

\section{DISCUSSION}

\section{Methodological considerations}

In this study of potential risk factors for suicide in psychiatric patients we achieved a satisfactory overall case note retrieval rate $(84 \%)$, which makes bias as a result of lost or destroyed case notes unlikely. All suicide cases were confirmed as such by examination of clinical records and death certificates, but some cases could have been missed if the coroners' verdicts were other than suicide or open. Our data on inpatient status were obtained from the ORLS. If a hospital admission was not recorded, then these cases would have been missed, but this would not have biased our findings.

One weakness of the study is that the rating of the presence of risk factors was not blind to case-control status. However, blinding would have been difficult to achieve: the last entry in all sets of case notes would have to have been removed, in addition to any reference to the suicide - including the writing of 'deceased' on the cover of the notes. The main measures used to avoid observer bias were the prior statement of the putative risk factors of interest, and the use of specific criteria for defining exposure to a potential risk factor.

Another limitation is that the identification of risk factors largely relied on criteria recorded in case notes. We cannot determine how accurate or complete these were, but it is likely that there was a degree of misclassification in the measurement of the risk factors. A prospective study might avoid many of these problems but the rarity of suicide means that such a study would have to be extremely large.

\section{Descriptive data}

Our finding that many in-patient suicides occur outside the hospital site confirms that in previous studies (Fernando \& Storm, 1984; Morgan \& Priest, 1991; Proulx et al, 1997; Sharma et al, 1998). The fact that the most common method of suicide was drowning was probably because this method was easily available: for instance, 22 of 31 drownings took place in rivers adjacent to or near hospital sites. The high number of women committing suicide by drowning is striking. 
Table 2 Case-control comparisons of possible risk factors for in-patient suicide

\begin{tabular}{|c|c|c|c|c|c|}
\hline Risk factor & Cases (\%) & Controls (\%) & OR $(95 \% \mathrm{Cl})$ & $P$ & $\begin{array}{c}\text { Adjusted OR }(95 \% \mathrm{Cl}) \\
\text { (adjusted for presence of } \\
\text { suicidal ideation) }\end{array}$ \\
\hline Male & $47 / 97(48)$ & $45 / 90(50)$ & $1.0(0.6-1.9)$ & 0.8 & \\
\hline Mean age (s.d.) & 45.1 (14.9) & $41.7(15.5)$ & - & & \\
\hline Age $<45$ years & $51 / 97(53)$ & $34 / 90(38)$ & $1.8(1.0-3.3)$ & 0.04 & \\
\hline Recent bereavement & $12 / 94(13)$ & $4 / 90(4)$ & $3.2(1-10.2)$ & 0.06 & $4.5(1.2-16.8)$ \\
\hline Relationship difficulties & $31 / 94(33)$ & $29 / 90(32)$ & $0.9(0.5-1.5)$ & 0.8 & \\
\hline Recent other life event & $3 / 94(3)$ & $5 / 90(6)$ & $0.6(0.1-2.4)$ & 0.7 & \\
\hline Depressed mood & $78 / 97(80)$ & $5 \mathrm{I} / 90(57)$ & $3.1(1.6-6.0)$ & 0.002 & $1.5(0.7-3.3)$ \\
\hline Angry or irritable & $5 / 97(5)$ & $9 / 90(10)$ & $0.4(0.1-I .5)$ & 0.17 & \\
\hline Delusions & $34 / 96(35)$ & $14 / 90(16)$ & $3.0(1.5-6.0)$ & 0.002 & $2.9(1.3-6.6)$ \\
\hline Hallucinations & $15 / 96(16)$ & $12 / 90(13)$ & I. $2(0.5-2.7)$ & 0.7 & \\
\hline Hopelessness & $47 / 94(50)$ & $15 / 90(17)$ & $5.0(2.5-10.0)$ & $<0.001$ & $2.3(1.1-5.2)$ \\
\hline Worthlessness or guilt & $44 / 94(47)$ & $19 / 90(2 I)$ & $3.3(1.7-6.3)$ & $<0.001$ & $1.9(0.9-4.0)$ \\
\hline \multicolumn{6}{|l|}{ Suicidal thoughts } \\
\hline None (baseline) & $23 / 97(24)$ & $68 / 90(76)$ & I & & - \\
\hline Some ideas, no plan & $17 / 97(18)$ & $10 / 90(11)$ & $5.0(2-12.5)$ & & - \\
\hline Plan, not acted upon & $4 / 97(4)$ & $\mathrm{I} / 90(\mathrm{I})$ & II.8 (I.3-III.3) & & - \\
\hline $\begin{array}{l}\text { Act of self-harm either leading to, } \\
\text { or during, admission }\end{array}$ & $53 / 97(55)$ & $11 / 90(12)$ & $14.3(6.4-31.8)$ & $<0.001$ & - \\
\hline Evidence of poor relationship with staff & $11 / 96(12)$ & $18 / 90(20)$ & $0.8(0.5-1.2)$ & 0.3 & \\
\hline On continuous observation during admission & $2 / 96(2)$ & $0 / 90(0)$ & - & 0.17 & \\
\hline $\begin{array}{l}\text { Previous self-harm (not including acts leading to } \\
\text { or during index admission) }\end{array}$ & $52 / 97(54)$ & $23 / 90(26)$ & $3.4(1.8-6.3)$ & $<0.001$ & $2.2(1.1-4.5)$ \\
\hline Chronic mental illness ( $>5$ years) & $27 / 97(28)$ & $13 / 90(14)$ & $2.7(1.5-5.1)$ & 0.002 & $2.9(1.4-6.2)$ \\
\hline Previous diagnosis of schizophrenia & $29 / 97(30)$ & $16 / 90(18)$ & $2.0(1.0-4.0)$ & 0.06 & $1.8(0.8-4.2)$ \\
\hline Previous diagnosis of depression & $59 / 97(61)$ & $38 / 90(42)$ & $2.0(1.1-3.5)$ & 0.07 & \\
\hline Previous diagnosis of personality disorder & $9 / 97(9)$ & $12 / 90(13)$ & $0.7(0.2-1.8)$ & 0.4 & \\
\hline Chronic physical illness & $6 / 97(6)$ & $7 / 90(8)$ & $0.8(0.3-2.4)$ & 0.7 & \\
\hline Extrapyramidal side-effects & $3 / 95(3)$ & $2 / 90(2)$ & $0.9(0.7-1.2)$ & 0.7 & \\
\hline First-degree relative commited suicide & $12 / 94(13)$ & $3 / 89(3)$ & $4.2(1.1-15.4)$ & 0.03 & $5.0(1.2-21.7)$ \\
\hline First-degree relative with psychiatric illness & $36 / 94(38)$ & $25 / 89(28)$ & $1.6(0.9-3.0)$ & 0.14 & \\
\hline No educational qualifications & $49 / 95(52)$ & $59 / 88(67)$ & $1.8(0.9-3.9)$ & 0.4 & \\
\hline Single & $29 / 97(30)$ & $21 / 84(25)$ & I.I (0.6-I.9) & 0.8 & \\
\hline Living alone & $22 / 96(23)$ & $23 / 90(26)$ & $0.9(0.4-1.7)$ & 0.7 & \\
\hline Unemployed & $24 / 96(25)$ & $30 / 90(33)$ & $0.7(0.4-1.3)$ & 0.2 & \\
\hline Has dependents & $32 / 96(33)$ & $32 / 90(36)$ & $0.9(0.5-1.7)$ & 0.8 & \\
\hline Current drug abuse & $3 / 95(3)$ & $14 / 90(16)$ & $0.2(0.0-0.6)$ & 0.008 & $0.3(0.1-1.4)$ \\
\hline Current alcohol abuse & $6 / 95(6)$ & $25 / 90(28)$ & $0.2(0.1-0.5)$ & $<0.001$ & $0.2(0.1-0.5)$ \\
\hline Conviction or caution for any offence & $6 / 95(6)$ & $20 / 90(22)$ & $0.2(0.1-0.6)$ & 0.003 & $0.6(0.2-1.6)$ \\
\hline Prison sentence for any offence & $\mathrm{I} / 95(\mathrm{I})$ & $13 / 90(14)$ & $0.1(0.0-0.5)$ & 0.008 & $0.2(0.0-0.7)$ \\
\hline
\end{tabular}

MHA, Mental Health Act 1983.

\section{Possible risk factors}

The variable with the strongest association with suicide was suicidal thoughts or acts - there was a 'dose-response' between the apparent strength of suicidal thoughts, as measured by the extent to which the patient had acted on the ideation, and the risk of suicide. A recent descriptive UK study has also identified suicidal ideation as of paramount importance in the assessment of risk (Morgan \& Stanton, 1997). Our findings extend those of previous work and confirm the importance of suicidal thoughts or activity as the most important 
Table 3 Likelihood ratios and post-test probabilities of the factors predictive of in-patient suicide

\begin{tabular}{|c|c|c|c|c|}
\hline Risk factor & $\begin{array}{l}\text { Crude likelihood ratio } \\
\qquad(95 \% \mathrm{Cl})\end{array}$ & $\begin{array}{l}\text { Adjusted likelihood ratio } \\
\qquad(\mathrm{ALR})^{\prime}\end{array}$ & $\begin{array}{l}\text { Final model likelihood } \\
\text { ratio (FMLR) }\end{array}$ & $\begin{array}{l}\text { Post-test probability } \\
\text { (using FMLR) }\end{array}$ \\
\hline \multicolumn{5}{|l|}{ Suicidal thoughts } \\
\hline None (baseline) & $0.3(0.2-0.5)$ & 0.4 & 0.3 & \\
\hline Some ideas, no plan & $1.6(0.8-3.2)$ & 1.5 & 1.6 & 0.002 \\
\hline Plan, not acted upon & $3.7(0.6-24.5)$ & 3.1 & 4.1 & 0.006 \\
\hline $\begin{array}{l}\text { Act of self-harm either leading to, or during, } \\
\text { admission }\end{array}$ & $4.5(2.6-8.1)$ & 3.7 & 4.9 & 0.007 \\
\hline Recent bereavement & $2.9(1.0-8.2)$ & 5.3 & 3.9 & 0.006 \\
\hline Depressed mood & $\mathrm{I} .4(\mathrm{I} .2-\mathrm{I} .8)$ & 1.0 & & \\
\hline Delusions & $2.3(1.4-4.0)$ & 2.3 & 2.2 & 0.003 \\
\hline Hopelessness & $3.0(1.9-5.0)$ & 1.8 & & \\
\hline Worthlessness or guilt & $2.2(1.4-3.5)$ & 1.3 & & \\
\hline $\begin{array}{l}\text { Previous self-harm (not including acts leading to or } \\
\text { during index admission) }\end{array}$ & $2.1(1.4-3.2)$ & 1.6 & & \\
\hline Chronic mental illness ( $>5$ years) & $1.9(1.1-3.5)$ & 1.9 & 2.2 & 0.003 \\
\hline One or more previous admission & $1.3(1.0-1.5)$ & 1.2 & & \\
\hline First-degree relative commited suicide & $3.8(1.2-12.2)$ & 3.3 & 4.6 & 0.007 \\
\hline
\end{tabular}

I. The method does not allow calculation of standard errors for adjusted likelihood ratios.

risk factor for suicide in psychiatric inpatients.

One of the most striking findings of the study is that some of the factors associated with suicide in the general population (being male, single, living alone, being unemployed, substance abuse) (Charlton et al, 1993), were not associated with suicides by hospital in-patients. This finding, which is clearly important in risk assessment, is consistent with previous case-control studies investigating risk factors for suicide following discharge from psychiatric hospital (Dennehy et al, 1996; Appleby et al, 1999b). The explanation may be that these factors are strongly

Table 4 Risk of suicide in the psychiatric in-patients on admission: characteristics of the final model of factors predictive of suicide.

\begin{tabular}{lcc}
\hline Risk of suicide & $\begin{array}{c}\text { Cases } \\
n(\%)\end{array}$ & $\begin{array}{c}\text { Controls } \\
n(\%)\end{array}$ \\
\hline$>5 \%$ & $2(2)$ & 0 \\
$>1 \% \leqslant 5 \%$ & $24(25)$ & $1(1)$ \\
$\leqslant 1 \%$ & $71(73)$ & $89(99)$ \\
& 97 & 90
\end{tabular}

Use of a cut-off point of $5 \%$ to denote 'at risk': sensitivity $2.1 \%$, i.e. $2 / 97$ ( $95 \% \mathrm{Cl} 0.3-7.3 \%$ ); specificity $100 \%$, i.e. $90 / 90$ (95\% Cl $96.0-100 \%)$.

Use of a cut-off point of $1 \%$ to denote 'at risk': sensitivity $26.8 \%$, i.e. $24 / 97$ (95\% Cl 18.3-36.8\%); specificity $98.9 \%$, i.e. $89 / 90$ ( $95 \% \mathrm{Cl} 94.0-100 \%)$. associated with both admission to psychiatric hospitals and suicidal ideation.

Substance abuse was associated with a reduced risk of suicide: it may be that patients admitted for these problems are not as acutely mentally ill (often being admitted for detoxification) as some other patients and do not have the same suicide risk.

\section{Comparison with similar studies}

Although there have been several descriptive studies of in-patient suicide in the UK (Copas \& Robin, 1982; Langley \& Bayatti, 1984; Morgan \& Priest, 1991), there have been no UK case-control studies. We are aware of four case-control studies of psychiatric hospital suicides worldwide that included only in-patients (Modestin et al, 1992; Read et al, 1993; Roy \& Draper, 1995; Sharma et al, 1998). These had fewer cases than our study and applied univariate analysis only. One was restricted to patients with schizophrenia (Modestin et al, 1992). In two others the diagnosis of schizophrenia was found to be a risk factor, while in the fourth the most common diagnosis was a mood disorder (Read et al, 1993; Roy \& Draper, 1995; Sharma et al, 1998). It has been shown that previous self-harm, in particular during the index admission, is one of the most potent risk factors (Modestin et al, 1992; Read et al, 1993; Roy \& Draper, 1995; Sharma et al, 1998). Compulsory admission was not identified as a risk factor in our study, but has been in others (Roy \& Draper, 1995; Sharma et al, 1998). This may be due to differences in the content and application of mental health legislation. Our study suggests that a history of suicide in a first-degree relative is a possible risk factor for in-patient suicide. There was no significant difference between cases and controls regarding history of psychiatric illness in a first-degree relative. One other casecontrol study which investigated family history found that in-patient suicide cases were more likely to have a family history of psychiatric problems, but were not significantly different regarding a family history of suicide (Sharma et al, 1998). It is not clear whether that study restricted the definition of 'family history' to first-degree relatives.

An association between chronic mental illness and in-patient suicide was shown in one study (Modestin et al, 1992), but not in the other studies that looked at this possibility (Read et al, 1993; Sharma et al, 1998). Other studies have not identified a relationship between abuse of alcohol or illicit drugs and the risk of in-patient suicide (Read et al, 1993; Roy \& Draper, 1995).

\section{Prediction and prevention of suicide by in-patients}

The reason for identifying factors associated with suicide by in-patients is that 
such knowledge may be useful in helping to identify individuals at risk and to prevent suicides occurring. Previous studies have attempted to develop models to predict which psychiatric patients might commit suicide (Pokorny, 1983; Goldstein et al, 1991), but have been unable to generate models with sufficiently high sensitivity and specificity to be any good at predicting such a rare event. In the present study, we have attempted to identify possible risk factors for suicide in patients in psychiatric hospitals - a particularly high-risk group.

Our model suggested that $30-40 \%$ of in-patients with all five risk factors would commit suicide, as would $5 \%$ of those with three or four risk factors. Expressed at the level of the individual patient, a $5 \%$ risk means that, for the individual, there is a 1 in 20 risk of suicide while in in-patient care. However, the clinical usefulness of these findings is limited because such combinations of risk factors are extremely rare. Among the 97 suicides included in our data set, only one had all five risk factors and only one other had a predicted risk of suicide of $>5 \%$. Reducing the threshold of concern to a $1 \%$ risk of suicide would have identified over $25 \%$ of those who committed suicide. The majority of those who committed suicide had predicted risks of suicide below $1 \%, 14 \%$ had no risk factors and $30 \%$ had only one risk factor. The model would therefore not have been able to predict the majority of the actual suicides without having an unacceptable (>99\%) false positive rate. On the other hand, using the presence of three, four or five predictive factors as rough clinical guides (see Results) may correctly identify a small number of patients as being at high risk. However, the reliability of the predictive model we have developed is uncertain, because it has not been validated in a second independent data set. It should be feasible to test the model in independent data sets derived from other large-scale record linkage studies.

The suicide of a psychiatric hospital inpatient is a rare but important event. As well as the grief caused to family and friends, and the significant effects it can have on other patients, it also raises questions of responsibility and guilt for the professionals involved in caring for the patient. This study suggests that, unless a very high number of false positives is considered acceptable, it is unavoidable that clinicians will fail to identify beforehand a high proportion of suicides, even

\section{CLINICAL IMPLICATIONS}

- We found that suicide by psychiatric hospital in-patients was strongly associated with suicidal ideas or acts of self-harm preceding or during admission.

- Five predictors had adjusted likelihood ratios greater than 2: recent bereavement, presence of delusions, suicidal ideation, chronic mental illness and family history of suicide. A patient with any three or more (or delusions plus chronic mental illness plus two others) of the five predictors would have a risk of suicide of over $5 \%$.

- Only $2 \%$ of those patients with a I in 20 risk of suicide or higher were correctly identified by the predictors.

\section{LIMITATIONS}

- The clinical and socio-demographic information on cases and controls was largely determined from retrospective examination of case notes, and the completeness of such information may vary. Also, the recording of information from case notes was not carried out blind to case-control status.

- All suicide cases were confirmed as such by examination of clinical records and death certificates, but some cases could have been missed if the coroner's verdict was other than suicide or open.

- The predictive model has not been validated in an independent data set.

JOHN POWELL, MRCPsych, JOHN GEDDES, MRCPsych, KEITH HAWTON, FRCPsych, Department of Psychiatry, University of Oxford, Warneford Hospital, Oxford; JONATHAN DEEKS, MSc, ICRF/NHS Centre for Statistics in Medicine, Institute of Health Sciences, Headington, Oxford; MICHAEL GOLDACRE, MSc, FFHPM, Unit of Health-Care Epidemiology, University of Oxford

Correspondence: Dr John Geddes, Warneford Hospital, Oxford OX37JX. Tel: 01865226480 , fax: 01865 793।0I,e-mail: john.geddes@psych.ox.ac.uk

(First received 31 March 1999, final revision 31 August 1999, accepted 2 September 1999)

in a high-risk group such as psychiatric hospital in-patients.

\section{ACKNOWLEDGEMENTS}

Supported in part by grants from Oxford and Anglia Regional Health Authority and Oxfordshire Health Authority. J.P. was funded by the Wellcome Trust as a research registrar in psychiatry on the Oxford rotational training scheme. K.H. is supported by Oxfordshire Mental Healthcare NHS Trust and South East Regional NHSE Research and Development Committee.

We thank Ed Juszczak and Doug Altman for statistical advice during this project.

\section{REFERENCES}

Appleby, L. (1992) Suicide in psychiatric patients: risk and prevention. British Journal of Psychiatry, 161, 749-758
_, Shaw, J., Amos, J., et al (1999a) Safer Services. Report of the National Confidential Inquiry into Suicide and Homicide by People with Mental IIIness. London: Stationery Office.

_, Dennehy, J. A., Thomas, C. S., et al (1999b) Aftercare and clinical characteristics of people with mental illness who commit suicide: a case-control study. Lancet, 353, 1397-1400.

Blain, P. A. \& Donaldson, L. J. (1995) The reporting of inpatient suicides: identifying the problem. Public Health, 109, 293-30।.

Charlton, J., Kelly, S., Dunnell, K., et al (1993) Suicide deaths in England and Wales: trends in factors associated with suicide deaths. Population Trends, $7 \mathbf{I}$ 34-42.

Copas, J. B. \& Robin, A. (1982) Suicide in psychiatric in-patients. British Journal of Psychiatry, 14I, 503-51।.

Dean, A. G., Dean, J. A., Coulombier, D., et al (1995) Epi Info, Version 6: A Word-Processing, Database, and Statistics Program for Public Health on IBM-compatible Microcomputers. Atlanta, GA: Centers for Disease Control and Prevention. 
Dennehy, J. A., Appleby, L., Thomas, C. S., et al (1996) Case-control study of suicide by discharged psychiatric patients. British Medical Journal, 312, I580.

Feinstein, A. R. (1977) Clinical biostatistics $X X X \mid X$ : The haze of Bayes, the aerial palaces of decision analysis, and the computerized Ouija board. Clinical Pharmacology and Therapeutics, 2I, 482-496.

Fernando, S. \& Storm, V. (1984) Suicide among psychiatric patients of a district general hospital. Psychological Medicine, 14, 661-672.

Geddes, J. R. (1999) Suicide and homicide in mentally il patients. British Medical Journal, 318, 1225-1226.

Goldacre, M. J., Simmons, H., Henderson, J., et al (1988) Trends in episode-based and person-based rates of admission to hospital in the Oxford Record Linkage Study area. British Medical Journal, 296, 583-584.

Goldstein, R. B., Black, D.W., Nasrallah, A., et al (1991) The prediction of suicide. Sensitivity, specificity, and predictive value of a multivariate model applied to suicide among 1906 patients with affective disorders. Archives of General Psychiatry, 48, 418-422.

Hawton, K. (1987) Assessment of suicide risk. British Journal of Psychiatry, I50, 145-153.
Langley, G. E. \& Bayatti, N. N. (1984) Suicides in Exe Vale Hospital, 1972-1981. British Journal of Psychiatry, I45, $463-467$.

McGuffin, P., Farmer, A. E. \& Harvey, I. (199I) A polydiagnostic application of operational criteria in studies of psychotic illness: development and reliability of the OPCRIT system. Archives of General Psychiatry, 48, 764-770.

Modestin, J., Zarro, I. \& Waldvogel, D. (1992) A study of suicide in schizophrenic in-patients. British journal of Psychiatry, 160, 398-40I.

Morgan, H. G. \& Priest, P. (1991) Suicide and other unexpected deaths among psychiatric in-patients. The Bristol confidential inquiry. British Journal of Psychiatry I58, 368-374.

— \& Stanton, R. (1997) Suicide among psychiatric in-patients in a changing clinical scene. Suicidal ideation as a paramount index of short-term risk. British Journal of Psychiatry, I7I, 56I-563.

Pokorny, A. D. (1983) Prediction of suicide in psychiatric patients. Report of a prospective study. Archives of General Psychiatry, 40, 249-257.
Proulx, F., Lesage, A. D. \& Grunberg, F. (1997) One hundred in-patient suicides. British Journal of Psychiatry, I7I, 247-250.

Read, D. A., Thomas, C. S. \& Mellsop, G.W. (1993) Suicide among psychiatric inpatients in the Wellington region. Australian and New Zealand journal of Psychiatry, 27, 392-398.

Roy, A. \& Draper, R. (1995) Suicide among psychiatric hospital inpatients. Psychological Medicine, 25, 199-202.

Sharma, V., Persad, E. \& Kueneman, K. (1998) A closer look at inpatient suicide. Journal of Affective Disorders, 47, 123-129.

Spiegelhalter, D. J. \& Knill-Jones, R. P. (1984)

Statistical and knowledge-based approaches to clinical decision-support systems, with an application in gastroenterology. Journal of the Royal Statistical Society, 147, 35-77.

SPSS (1997) SPSS 8.0 for Windows. Chicago, IL: SPSS

StataCorp (1999) Stata Statistical Software: Release 6.0. College Station, TX: Stata Corporation.

Statistics and Epidemiology Research Corporation (199I) EGRET. Seattle,WA: SERC. 